\title{
Studies of association of AGPAT6 variants with type 2 diabetes and related metabolic phenotypes in 12,068 Danes
}

\author{
Lena Sønder Snogdal ${ }^{1,2^{*}}$, Niels Grarup ${ }^{3}$, Karina Banasik ${ }^{3}$, Mette Wod ${ }^{1,2}$, Torben Jørgensen ${ }^{4,5}$, Daniel R Witte ${ }^{6}$, \\ Torsten Lauritzen ${ }^{7}$, Aneta A Nielsen ${ }^{8}$, Ivan Brandslund ${ }^{8,9}$, Cramer Christensen ${ }^{10}$, Oluf Pedersen ${ }^{3,11,12}$, \\ Knud Yderstræde ${ }^{1}$, Henning Beck-Nielsen ${ }^{1}$, Jan Erik Henriksen ${ }^{1}$, Torben Hansen ${ }^{2,3}$ and Kurt Højlund ${ }^{1,2}$
}

\begin{abstract}
Background: Type 2 diabetes, obesity and insulin resistance are characterized by hypertriglyceridemia and ectopic accumulation of lipids in liver and skeletal muscle. AGPAT6 encodes a novel glycerol-3 phosphate acyltransferase, GPAT4, which catalyzes the first step in the de novo triglyceride synthesis. AGPAT6-deficient mice show lower weight and resistance to diet- and genetically induced obesity. Here, we examined whether common or low-frequency variants in AGPAT6 associate with type 2 diabetes or related metabolic traits in a Danish population.

Methods: Eleven variants selected by a candidate gene approach capturing the common and low-frequency variation of AGPAT6 were genotyped in 12,068 Danes from four study populations of middle-aged individuals. The case-control study involved 4,638 type 2 diabetic and 5,934 glucose-tolerant individuals, while studies of quantitative metabolic traits were performed in 5,645 non-diabetic participants of the Inter99 Study.

Results: None of the eleven AGPAT6 variants were robustly associated with type 2 diabetes in the Danish case-control study. Moreover, none of the AGPAT6 variants showed association with measures of obesity (waist circumference and BMI), serum lipid concentrations, fasting or 2-h post-glucose load levels of plasma glucose and serum insulin, or estimated indices of insulin secretion or insulin sensitivity.

Conclusions: Common and low-frequency variants in AGPAT6 do not significantly associate with type 2 diabetes susceptibility, or influence related phenotypic traits such as obesity, dyslipidemia or indices of insulin sensitivity or insulin secretion in the population studied.
\end{abstract}

Keywords: Type 2 diabetes, Genetics, Insulin resistance, Human, Lipid droplets, AGPAT6, GPAT4

\section{Background}

Lipid droplets are universal cellular organelles that store neutral lipids, such as sterol esters and triglycerides. Lipid droplets are the main reservoir of energy storage, and provide phospholipids for membrane synthesis, and protect cells from the lipotoxic effects of unesterified lipids [1]. Adipose tissue is the main site of lipid storage. However,

\footnotetext{
*Correspondence: Iss@dadlnet.dk

'Department of Endocrinology, Diabetes Research Center, Odense University Hospital, Odense, Denmark

${ }^{2}$ Section of Molecular Diabetes \& Metabolism, Institute of Clinical Research \& Institute of Molecular Medicine, University of Southern Denmark, Odense, Denmark

Full list of author information is available at the end of the article
}

type 2 diabetes, obesity and insulin resistance are characterized by hypertriglyceridemia and ectopic lipid storage in various non-adipose tissues. Thus, several studies have reported an association between accumulation of intramyocellular triglycerides and insulin resistance [2-5], and the excessive accumulation of lipids in skeletal muscle, liver and heart and a potential lipotoxic effect on betacells has been linked to the pathogenesis of insulin resistance and type 2 diabetes [6-8]. Genetic and acquired syndromes of lipodystrophy are characterized by the inability to store lipids in adipose tissues. This causes hypertriglyceridemia and ectopic deposition of lipids in skeletal muscle and liver, and is associated with severe insulin resistance in the absence of obesity [9]. Variants in genes

\section{Ciomed Central}

(c) 2013 Snogdal et al.; licensee BioMed Central Ltd. This is an open access article distributed under the terms of the Creative Commons Attribution License (http://creativecommons.org/licenses/by/2.0), which permits unrestricted use, distribution, and reproduction in any medium, provided the original work is properly cited. 
coding for tissue-specific enzymes involved in de novo phospholipid and triglyceride biosynthesis or proteins regulating the formation of lipid droplets could potentially disturb the balance between storage of lipids in adipose tissues and ectopic lipid deposition in non-adipose tissues as mentioned above $[1,10]$, and hence contribute to the pathogenesis of insulin resistance and type 2 diabetes.

The first committed step in de novo triglyceride synthesis is the acylation of glycerol-3-phosphate leading to the formation of lysophosphatidic acid [10]. This reaction, which has been considered to be rate-limiting, is catalyzed by glycerol-3-phosphate acyltransferases (GPATs), of which four isoforms have been identified in mammals [10]. GPAT4, which is encoded by AGPAT6, is the most recently identified GPAT $[11,12]$. It was initially classified as a acylglycerol-3-phosphate O-acyltransferase (AGPAT), but later studies found it to be the second microsomal GPAT localized to the endoplasmatic reticulum [10,11]. In mice, AGPAT6 is highly expressed in brown adipose tissue (BAT), white adipose tissue (WAT) and liver [13,14], whereas in humans, AGPAT6 mRNA seems to be more ubiquitously expressed with the highest expression in testis, and brain, but also in adipose tissues and skeletal muscle $[11,15]$. Recent studies have reported that microsomal GPAT activity is enhanced by insulin, and that this may involve insulin-stimulated phosphorylation of the microsomal GPAT3 and GPAT4, implying their importance in insulin action on lipogenesis [14]. Studies of agpat6-/-knock-out mice have shown that loss of GPAT4 activity causes a $25 \%$ reduction in body weight and resistance to both diet- and genetically induced obesity. This was associated with increased energy expenditure, reduced triglyceride storage in BAT and WAT and liver, and subdermal lipodystrophy $[10,12,13]$. Based on the lessons learned from the agpat6-deficient mice, we hypothesized that variation in the human AGPAT6 may associate with obesity, hypertriglyceridemia, insulin resistance and type 2 diabetes susceptibility.

The aim of the present study was to investigate whether common and low-frequency variation in AGPAT6, encoding a novel GPAT enzyme, GPAT4, was associated with type 2 diabetes, obesity, dyslipidemia or indices of insulin resistance and insulin secretion in a large Danish population.

\section{Methods}

Participants In total 11 AGPAT6 variants were genotyped in 12,068 individuals ascertained from five different Danish study groups: 1) The Inter99 cohort, which is a population-based, randomized, non-pharmacological intervention study of middle-aged individuals for the prevention of ischaemic heart disease $(n=6,287)$ conducted at the Research Centre for Prevention and Health in Glostrup, Copenhagen (ClinicalTrials.gov ID-no: NCT00289237)
[16]; 2) type 2 diabetic patients $(n=1,575)$ from the population-based, ADDITION Denmark screening study cohort (Anglo-Danish-Dutch Study of Intensive Treatment in People with Screen-Detected Diabetes in Primary Care) (ClinicalTrials.gov ID-no: NCT00237548) [17]; 3) unrelated type 2 diabetic patients $(n=1,658)$ examined at the out-patient clinic at Steno Diabetes Center, Copenhagen, Denmark; 4) a population-based group of unrelated middle-aged individuals $(n=567)$ also sampled at Steno Diabetes Center, and 5) a sample of type 2 diabetic patients and age-matched non-diabetic control persons enrolled in the former Vejle County $(n=1,981)$. The type 2 diabetes inclusion criteria in all study groups fulfilled the diagnostic criteria according to the WHO 1999. Clinical characteristics of the five study groups are given in Additional file 1: Table S1. All participants were Danes by self-report and all gave informed written consent before participation. We do not have specific information on ethnicity yet all study participants are of Danish nationality. In other studies of the same study material we have by chip genotyping data looked at population outliers and did not observe ethnical population outliers [18]. The studies were performed in accordance with the principles of the Helsinki Declaration and all studies were approved by the local ethics committees (Ethical Committee of Copenhagen: \#KA 98155, \#KA95117g, \#KA95117gm, \#KA94092g, \#KA96008; Ethical Committee of Aarhus: \#2000183; Ethical Committee of Region of Southern Denmark: \#S-20080097).

Type 2 diabetic patients from study groups $1(\mathrm{n}=328)$, $2(n=1,575), 3(n=1,658), 4(n=47)$ and $5(n=1,030)$ were included in the case-control studies. Control individuals had normal fasting glucose according to WHO 1999 criteria [19] (study group $5(\mathrm{n}=951)$ ) or had normal fasting glucose and normal glucose tolerance during a standard 75 g OGTT (study groups $1(\mathrm{n}=4,463)$ and 4 $(\mathrm{n}=520))$. No pre-diabetics were included in the study. In total, the case-control studies included 4,638 type 2 diabetic and 5,934 control individuals. Studies of quantitative traits were performed in 5,645 participants of the Inter99 cohort excluding individuals with type 2 diabetes and screen-detected type 2 diabetes.

SNP selection We performed tagging of the genomic region including AGPAT6 (HapMap release 27, Phase II + III, Feb. 09, B36, CEU panel; Chr8:41,544 kb - 41,607 kb (AGPAT6 position $\pm 10 \mathrm{~kb}$ )) using Haploview 4.2 (www. broadinstitute.org/haploview). See LD plot of AGPAT6 in Figure 1. Eleven SNPs captured all common variation with minor allele frequency (MAF) above $5 \%(n=10)$ and lowfrequency variation with MAF below $5 \%$ but above $1 \%$ $(\mathrm{n}=1)$ variation in AGPAT6 $\left(\mathrm{r}^{2}>0.8\right)$. The selected SNPs have the following rs numbers: rs13252523, rs7357415, rs2977860, rs11785763, rs999188, rs17600159, rs2977845, rs10504041, rs12677439, rs6988044 and rs890220. 


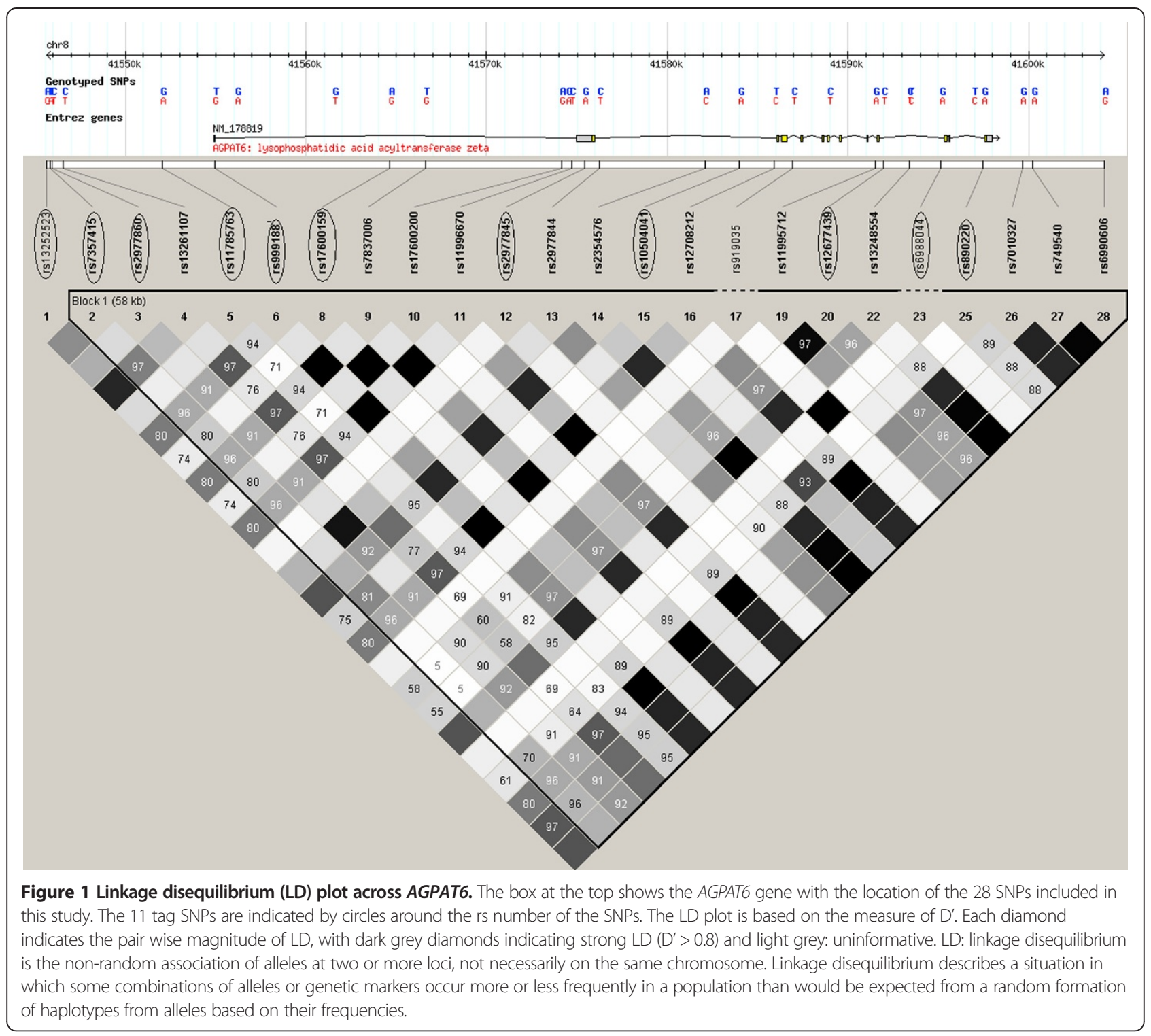

Biochemical and anthropometrical measures Body weight and height were measured in light indoor clothing and without shoes. Waist circumference was measured in the standing position midway between the iliac crest and the lower costal margin. Blood samples were drawn after a 12-h overnight fast. Serum insulin levels were measured by using the AutoDELFIA insulin kit (Perkin-Elmer, Wallac, Turku, Finland). Plasma glucose was analyzed by a glucose oxidase method (Granutest; Merck, Darmstadt, Germany). Serum triglyceride and cholesterols were determined by enzymatic colorimetric methods (GPO-PAP and CHOD-PAP, Roche Molecular Biochemicals).

Derived estimates of insulin response and insulin sensitivity from an OGTT Indices of oral glucose-stimulated insulin secretion are reported as the insulinogenic index calculated as ([serum insulin 30 min - serum insulin ${ }_{0}$ min $(\mathrm{pmol} / \mathrm{l})] /[\mathrm{plasma}$ glucose $30 \mathrm{~min}(\mathrm{mmol} / \mathrm{l})])$, and the BIGTTacute insulin response (AIR) index. The surrogate measures of insulin sensitivity $\left(\mathrm{S}_{\mathrm{I}}\right)$ are reported as the homeostasis model assessment of insulin resistance (HOMA-IR), Matsuda- $\mathrm{S}_{\text {I }}$, Stumvoll- $\mathrm{S}_{\mathrm{I}}$, and BIGTT-S , all calculated as described previously [20-23]. The BIGTT indices, which apply information on sex and BMI, combined with plasma glucose and serum insulin during an OGTT, were calculated as reported [21].

Genotyping The eleven AGPAT6 variants were genotyped using KASPar SNP Genotyping system (KBioscience, Hoddesdon, UK). Success-rates of the genotyping were above 95\% for all 11 SNPs. Error rates were below 0.5\% for the 11 variants, as estimated from re-genotyping of 596 duplicate samples. The distribution of genotypes was 
in Hardy-Weinberg equilibrium in the population-based Inter99 for all SNPs ( $\mathrm{p}>0.05)$.

Statistical power The statistical power in type 2 diabetes case-control studies were calculated using the CaTS power calculator for large genetic association studies (available at http://www.sph.umich.edu/csg/abecasis/ cats/). The power calculations assumed a Bonferroni adjusted alpha-value of $0.05 / 11=0.0045$, a disease prevalence of $8 \%$ and MAFs $5-40 \%$ (Additional file 1: Figure S1). Given the MAFs for the 11 investigated AGPAT6 variants $(4.0 \%-46 \%)$, our study has statistical power of more than $80 \%$ to detect an odds ratio (OR) of 1.10 in a case-control design for the most common variants (MAF $\sim 40 \%$ ), whereas we have $\sim 80 \%$ power to detect an OR of 1.20-1.25 for the lower frequency variants (MAF 5\%). The statistical power calculations for quantitative traits were performed as previously described [15] and showed that we have statistical power of $94 \%$ to detect an effect equal to a fraction of a standard deviation of 0.08 for a SNP with a MAF of $46 \%$, while we had power $93 \%$ to detect an effect equal to a fraction of a standard deviation of 0.20 in case of a MAF 5\%. Our power calculations do not allow any solid conclusions. Additional file 1: Figure $\mathrm{S} 1$ is a graph showing power for a range of OR's and allele frequencies.

Statistics A case-control analysis of type 2 diabetes was performed using logistic regression to examine differences in genotypes assuming an additive genetic model with adjustment for sex and age. A general linear model was used to test quantitative variables for differences between genotype groups applying an additive model adjusted for age and sex. We also performed the analysis including BMI as covariate, however that did not add any information to the analysis and results are not shown. Values of serum insulin, Matsuda- $\mathrm{S}_{\mathrm{I}}$ and Stumvoll- $\mathrm{S}_{\mathrm{I}}$ were logarithmically transformed before analyses, since that was appropriate when checked for normality of the residuals. A p-value below a Bonferroni corrected threshold of $0.05 / 11=0.0045$ was considered to be significant, taking the 11 variants into account. All analyses were performed in RGui version 2.11.1 (available at http://www.r-project.org).

\section{Results}

Eleven common and low-frequency AGPAT6 variants were genotyped in 12,068 Danish individuals All the 11 genotyped AGPAT6 variants were in low pairwise linkage disequilibrium $\left(\mathrm{r}^{2}<0.46\right)$.

In case-control settings, four of the variants, rs 2977845 , rs10504041, rs6988044 and rs890220 were nominally associated with type 2 diabetes, when examined in 4,638 type 2 diabetes and 5,934 control individuals $(\mathrm{p}<0.05)$ (Table 1). For all the variants we calculated OR for the minor allele in a model adjusted for age and sex. Thus, carriers of the minor allele of rs2977845 (OR1.18 [95\% CI 1.01-1.37, $\mathrm{p}=0.034 \mathrm{]}$ ) had a nominally increased risk of type 2 diabetes, while carriers of the minor alleles of rs10504041 (OR 0.91 [95\% CI 0.84-0.99, $\mathrm{p}=0.030$ ]), rs6988044 (OR 0.87 [95\% CI $0.76-0.99, \mathrm{p}=0.030]$ ) and rs890220 (OR 0.88 [95\% CI 0.8-0.96, p=0.0052]) showed a nominally reduced susceptibility to type 2 diabetes. However, after correction for multiple testing none of the 11 variants were robustly associated with type 2 diabetes (Table 1). We performed lookup of the genotyped SNPs in results from the newest DIAGRAM genomewide association study (http://diagram-consortium.org/ downloads.html) [24]. Seven of the 11 SNPs were found in DIAGRAM results. For the correlated rs10504041 and rs890220 SNPs nominal association in DIAGRAM data was observed yet in the opposite direction compared to the present data (Additional file 1: Table S11). The minor $G$ allele of rs17600159 showed nominal association in DIAGRAM data (OR 1.10, $P=0.0041)$ but was not statistical significant in the current data (OR 1.12, $P=0.09$ ). (Additional file 1: Table S2).

We investigated the relationships of the 11 AGPAT6 variants with quantitative metabolic traits in the populationbased Inter99 cohort of 5,645 non-diabetic Danes. Based on its function as GPAT4 and lessons learned from agpat6-deficient mice, we focused on measures of obesity (BMI and waist), dyslipidemia (triglycerides, HDL-cholesterol and total-cholesterol), fasting and 2-h post-glucose load levels of insulin or glucose, and OGTT-derived indices of insulin sensitivity (HOMA-IR, BIGTT-S $\mathrm{S}_{\mathrm{I}}$, Stumvoll- $\mathrm{S}_{\mathrm{I}}$, Matsuda $\mathrm{S}_{\mathrm{I}}$ ) and insulin secretion (Insulinogenic index and BIGTT-AIR). All variants were analysed applying an additive genetic model adjusting for age and sex. The minor G-allele of rs17600159 showed nominal association with plasma glucose and insulin 2-h after an OGTT (Table 2). However, this was not significant after correction for multiple testing. For the minor A-allele of rs890220, which showed the most significant nominal association with type 2 diabetes, we observed no association with any of the examined metabolic traits (Table 3). Moreover, we could not demonstrate any association of the other nine AGPAT6 variants with these traits of obesity, dyslipidemia, insulin sensitivity or insulin secretion (Additional file 1: Tables S3-11). Adjustment for BMI in all analysis did not change the results substantially.

\section{Discussion}

Several studies have shown that ectopic deposition of triglycerides in lipid droplets is strongly associated with insulin resistance and plays an important role in the pathogenesis of type 2 diabetes [6-8,25]. This suggests that variation in genes related to de novo triglyceride synthesis and lipid droplet formation could be associated with type 2 diabetes or related metabolic traits. Here, we have tested whether common or low-frequency variation in AGPAT6, was associated with increased susceptibility 
Table 1 Type 2 diabetes association for the 11 AGPAT6 variants genotyped in type 2 diabetic individuals and control individuals with normal glucose tolerance

\begin{tabular}{|c|c|c|c|c|c|c|}
\hline \multirow[t]{3}{*}{ AGPAT6 variant } & \multicolumn{2}{|c|}{$\mathbf{N}$} & \multirow{3}{*}{$\begin{array}{l}\text { Minor:major } \\
\text { allele }\end{array}$} & \multirow[t]{3}{*}{ MAF } & \multirow{3}{*}{$\begin{array}{l}\text { Odds ratio } \\
(95 \% \mathrm{Cl})\end{array}$} & \multirow[t]{3}{*}{ P-value } \\
\hline & T2D & NGT & & & & \\
\hline & (wildtype/hetero-/homozygous) & (wildtype/hetero-/homozygous) & & & & \\
\hline rs13252523 & $1428 / 2304 / 802$ & $1821 / 2840 / 1148$ & G:A & 0.44 & $0.95(0.88-1.01)$ & 0.098 \\
\hline rs7357415 & 2779/1555/197 & $3546 / 1973 / 293$ & $\mathrm{~T}: \mathrm{A}$ & 0.22 & $0.95(0.87-1.03)$ & 0.19 \\
\hline rs2977860 & 2158/1931/386 & $2827 / 2419 / 478$ & $\mathrm{~T}: \mathrm{C}$ & 0.30 & $1.03(0.95-1.1)$ & 0.49 \\
\hline rs11785763 & $3364 / 1095 / 94$ & $4307 / 1405 / 116$ & G:A & 0.14 & $0.99(0.90-1.08)$ & 0.79 \\
\hline rs999188 & $1379 / 2271 / 875$ & 1802/2817/1169 & $\mathrm{T}: \mathrm{G}$ & 0.44 & $1.00(0.94-1.07)$ & 0.98 \\
\hline rs17600159 & $3941 / 581 / 13$ & $5123 / 658 / 16$ & G:A & 0.063 & $1.12(0.98-1.29)$ & 0.092 \\
\hline rs2977845 & $4124 / 433 / 12$ & $5332 / 513 / 15$ & G:A & 0.048 & $1.18(1.01-1.37)$ & 0.034 \\
\hline rs10504041 & 2980/1359/169 & $3738 / 1814 / 256$ & G:A & 0.19 & $0.91(0.84-0.99)$ & 0.030 \\
\hline rs12677439 & $2568 / 1709 / 271$ & $3374 / 2062 / 343$ & $\mathrm{~T}: \mathrm{C}$ & 0.24 & $1.06(0.99-1.15)$ & 0.11 \\
\hline rs6988044 & $3993 / 566 / 15$ & $5028 / 786 / 31$ & G:A & 0.069 & $0.87(0.76-0.99)$ & 0.030 \\
\hline rs890220 & $3376 / 1107 / 85$ & $4188 / 1468 / 151$ & $\mathrm{G}: \mathrm{A}$ & 0.15 & $0.88(0.80-0.96)$ & 0.0052 \\
\hline
\end{tabular}

P-values and odds ratios were calculated by logistic regression analysis assuming an additive genetic model and adjusting for age and sex. Effects were calculated for the minor allele. T2D Type 2 diabetes, NGT Normal glucose tolerance, MAF Minor allele frequency.

Table 2 Anthropometric and quantitative metabolic characteristics of 5,645 middle-aged Danish Inter99 participants stratified according to the AGPAT6 rs17600159 genotype

\begin{tabular}{|c|c|c|c|c|}
\hline AGPAT6 rs 17600159 & AA & GA & GG & $\mathrm{p}$ value \\
\hline $\mathrm{N}$ (men/women) & $4835(2373 / 2462)$ & $641(317 / 324)$ & 19(10/9) & \\
\hline Age (years) & $45.9 \pm 7.9$ & $45.8 \pm 7.5$ & $46.7 \pm 7.9$ & \\
\hline Waist (cm) & $85.9 \pm 12.9$ & $85.9 \pm 12.9$ & $90.7 \pm 12.9$ & 0.56 \\
\hline $\mathrm{BMI}\left(\mathrm{kg} / \mathrm{m}^{2}\right)$ & $26.0 \pm 4.4$ & $25.9 \pm 4.4$ & $27.8 \pm 5.1$ & 0.82 \\
\hline Serum Triglycerides (mmol/l) & $1.3 \pm 1.4$ & $1.3 \pm 1.1$ & $1.2 \pm 0.5$ & 0.34 \\
\hline Serum Total cholesterol $(\mathrm{mmol} / \mathrm{l})$ & $5.5 \pm 1.1$ & $5.5 \pm 1.0$ & $5.2 \pm 1.0$ & 0.92 \\
\hline Serum HDL cholesterol (mmol/l) & $1.4 \pm 0.4$ & $1.4 \pm 0.4$ & $1.4 \pm 0.3$ & 0.61 \\
\hline \multicolumn{5}{|l|}{ Plasma glucose $(\mathrm{mmol} / \mathrm{l})$} \\
\hline Fasting & $5.45 \pm 0.51$ & $5.47 \pm 0.51$ & $5.43 \pm 0.55$ & 0.36 \\
\hline $120 \mathrm{~min}$ & $5.93 \pm 1.52$ & $6.06 \pm 1.64$ & $6.76 \pm 1.57$ & 0.025 \\
\hline \multicolumn{5}{|l|}{ Serum insulin $(\mathrm{pmol} / \mathrm{l})$} \\
\hline Fasting & $41 \pm 26$ & $40.3 \pm 24.4$ & $41.8 \pm 22.7$ & 0.85 \\
\hline $120 \mathrm{~min}$ & $206 \pm 198$ & $212 \pm 184$ & $374 \pm 410$ & 0.013 \\
\hline \multicolumn{5}{|l|}{ Insulin secretion indices } \\
\hline Insulinogenic index & $29.8 \pm 19.7$ & $30.2 \pm 18.8$ & $35.0 \pm 30.4$ & 0.32 \\
\hline BIGTT-AIR & $1860 \pm 1096$ & $1859 \pm 1017$ & $2372 \pm 2177$ & 0.59 \\
\hline \multicolumn{5}{|l|}{ Insulin sensitivity indices } \\
\hline HOMA-IR (pmol x mmol/l) & $9.98 \pm 6.84$ & $9.95 \pm 6.42$ & $10.09 \pm 5.44$ & 0.80 \\
\hline BIGTT-S, & $9.49 \pm 3.94$ & $9.26 \pm 3.94$ & $7.97 \pm 4.42$ & 0.075 \\
\hline Stumvoll $S_{1}$ & $0.10 \pm 0.02$ & $0.10 \pm 0.02$ & $0.09 \pm 0.03$ & 0.34 \\
\hline Matsuda $S_{1}$ & $9.19 \pm 5.69$ & $8.94 \pm 5.69$ & $7.80 \pm 4.56$ & 0.15 \\
\hline
\end{tabular}

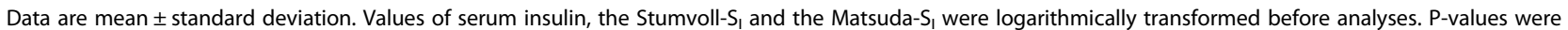
calculated assuming an additive genetic model with adjustment for age and sex. 
Table 3 Anthropometric and quantitative metabolic characteristics of 5,645 middle-aged Danish Inter99 participants stratified according to the AGPAT6 rs890220 genotype

\begin{tabular}{|c|c|c|c|c|}
\hline AGPAT6 rs890220 & AA & GA & GG & $\mathrm{p}$ value \\
\hline $\mathrm{N}$ (men/women) & 3995(1976/2019) & $1368(654 / 714)$ & $134(67 / 67)$ & \\
\hline Age (years) & $45.8 \pm 7.9$ & $46.3 \pm 7.7$ & $45.9 \pm 8.0$ & \\
\hline Waist (cm) & $85.9 \pm 13.0$ & $86.1 \pm 12.8$ & $83.3 \pm 12.1$ & 0.48 \\
\hline $\mathrm{BMI}\left(\mathrm{kg} / \mathrm{m}^{2}\right)$ & $26.0 \pm 4.5$ & $26.1 \pm 4.2$ & $25.4 \pm 4.0$ & 0.60 \\
\hline Serum Triglycerides (mmol/l) & $1.3 \pm 1.5$ & $1.3 \pm 0.9$ & $1.3 \pm 1.2$ & 0.50 \\
\hline Serum Total cholesterol $(\mathrm{mmol} / \mathrm{l})$ & $5.5 /-1.1$ & $5.6 \pm 1.0$ & $5.5 \pm 1.1$ & 0.084 \\
\hline Serum HDL cholesterol (mmol/l) & $1.4 \pm 0.4$ & $1.5 \pm 0.4$ & $1.4 \pm 0.4$ & 0.86 \\
\hline \multicolumn{5}{|l|}{ Plasma glucose $(\mathrm{mmol} / \mathrm{l})$} \\
\hline Fasting & $5.45 \pm 0.52$ & $5.47 \pm 0.50$ & $5.42 \pm 0.50$ & 0.74 \\
\hline $120 \mathrm{~min}$ & $5.95 \pm 1.56$ & $5.96 \pm 1.51$ & $5.76 \pm 1.50$ & 0.44 \\
\hline \multicolumn{5}{|l|}{ Serum insulin $(\mathrm{pmol} / \mathrm{l})$} \\
\hline Fasting & $41 \pm 27$ & $40 \pm 25$ & $39 \pm 23$ & 0.74 \\
\hline $120 \mathrm{~min}$ & $209 \pm 199$ & $201 \pm 189$ & $193 \pm 146$ & 0.63 \\
\hline \multicolumn{5}{|l|}{ Insulin secretion indices } \\
\hline Insulinogenic index & $29.7 \pm 19.3$ & $30.0 \pm 20.1$ & $33.0 \pm 23.1$ & 0.22 \\
\hline BIGTT-AIR & $1861 \pm 1088$ & $1852 \pm 1067$ & $1930 \pm 1210$ & 0.63 \\
\hline \multicolumn{5}{|l|}{ Insulin sensitivity indices } \\
\hline HOMA-IR (pmol x mmol/l) & $10.03 \pm 6.85$ & $9.96 \pm 6.796$ & $9.58 \pm 6.21$ & 0.81 \\
\hline BIGTT-S, & $9.44 \pm 4.00$ & $9.42 \pm 3.79$ & $9.54 \pm 3.73$ & 0.26 \\
\hline Stumvoll $S_{1}$ & $0.10 \pm 0.02$ & $0.10 \pm 0.02$ & $0.10 \pm 0.02$ & 0.085 \\
\hline Matsuda $S_{1}$ & $9.17 \pm 5.78$ & $9.04 \pm 5.34$ & $9.20 \pm 6.47$ & 0.85 \\
\hline
\end{tabular}

Data are mean \pm standard deviation. Values of serum insulin, the Stumvoll-S and the Matsuda- $\mathrm{S}_{\text {I }}$ were logarithmically transformed before analyses. P-values were calculated assuming an additive genetic model with adjustment for age and sex.

of type 2 diabetes or related metabolic traits. In contrast to our hypothesis, we could not demonstrate a robust association with type 2 diabetes for any of the eleven AGPAT6 variants investigated. Moreover, none of these variants were significantly associated with measures of adiposity, dyslipidemia or indices of insulin sensitivity or insulin secretion in a large cohort of non-diabetic, middleaged Danish individuals. These results indicate that common and low-frequency variation in the gene encoding the most recently identified glycerol-3-phosphate acyltransferase, GPAT4, does not play a major role in the presence or absence of prediabetic phenotypes or risk of type 2 diabetes.

In previous genome-wide association (GWA) studies of genetic variants contributing to type 2 diabetes risk [26-29], the majority of genes investigated included only variants with a MAF about $5 \%$ or higher. In none of these studies, variants in genes regulating de novo phospholipid or triglyceride synthesis or controlling lipid droplet formation have been found to be robustly associated with type 2 diabetes [30]. Here, we applied the candidate gene approach to capture not only common but also lowfrequency variation in AGPAT6 to examine its potential association with type 2 diabetes. However, in agreement with the GWA-studies, we were unable to show any robust association of genetic variation in AGPAT6 with type 2 diabetes in a Danish population. Yet, the statistical power of the current study does not allow for solid conclusions on the possible existence of common AGPAT6 variants with modest or subtle effect on disease risk. Also, this finding does not exclude that rare AGPAT6 variants with a MAF less than $1 \%$ may cause type 2 diabetes associated with e.g. lipodystrophy.

Studies of humans with acquired and genetic syndromes of lipodystrophy have clearly shown that failure of lipid storage in adipose tissues, hypertriglyceridemia and ectopic deposition of lipid in liver and skeletal muscle is associated with severe insulin resistance [9]. Mutations in AGPAT2, which is another gene involved in de novo triglyceride synthesis, is an accepted cause of congenital generalized lipodystrophy associated with extreme insulin resistance and early onset diabetes in humans [31], and the phenotype has been reproduced in agpat2-deficient mice [32]. Moreover, accumulation of triglycerides in skeletal muscle is negatively associated with insulin sensitivity even in a healthy population [2-5]. These findings, together with 
reports of lower weight, resistance to obesity and depletion of triglyceride in adipose tissues in agpat6-deficient mice, suggested a possible role for variation in AGPAT6 in relation to prediabetic phenotypes such as obesity, circulating levels of triglycerides and insulin resistance. However, at least in a non-diabetic population of Danish individuals, we were unable to demonstrate any significant association of common and low-frequency variation in AGPAT6 with these diabetes-related traits. These results are consistent with the absence of AGPAT6 variants among genetic variants shown to contribute to dyslipidemia and hypertriglyceridemia in current available GWA-studies [33].

The study has following limitations. First, the casecontrol analysis is limited by sample size. We cannot exclude association in our samples with odds ratios outside of the $95 \%$ confidential intervals, i.e. for rs 13252523 , we cannot exclude an association with type 2 diabetes with on odds ratio higher than 1.01 or lower than 0.88 . Secondly, although we corrected for multiple testing for the 11 variants, we did not correct for the number of phenotypes since they are not independent, and therefore would give an over-correction by Bonferroni. Another limitation of the present study is that association of AGPAT6 variants with insulin secretion and insulin sensitivity was based on OGTT-derived surrogate measures of these traits rather than application of gold-standard methods. A recent report indicates that, in particular, caution is required for the interpretation of differences in OGTT-derived values of insulin sensitivity, because such differences may reflect variations in beta-cell function rather than true variations in insulin sensitivity [34]. It would also have been interesting to examine association of these AGPAT6 variants with direct or indirect measures of ectopic lipid content in relevant target tissues such as liver and skeletal muscle, and with AGPAT6 expression and/or activity in these tissues. Nevertheless, so far there is no evidence from GWA studies that common variants in AGPAT6 associate with hepatic steatosis such as seen in non-alcoholic fatty liver disease $[35,36]$.

\section{Conclusions}

In summary, we here report that common and lowfrequency variation in AGPAT6 do not associate with type 2 diabetes, or related obvious metabolic phenotypes such as obesity, dyslipidemia or insulin resistance in a Danish population. Further studies are warranted to exclude a role for other genes involved in de novo triglyceride synthesis and lipid droplet formation.

\section{Additional file}

Additional file 1: Figure S1. Graph for power for a range of lower ORs and allele frequencies. Table S1 Clinical characteristics of the four study groups. Data are means \pm standard deviation. *, in the ADDITION study fasting glucose is measured on capillary blood. T2D, type 2 diabetes.
Table S2 Data on 7 of the SNPs from the newest DIAGRAM database. OR's are mean $\pm 95 \% \mathrm{Cl}$. T2D, type 2 diabetes; NGT, normal glucose tolerance; MAF, minor allele frequency. Table S3-S11 Anthropometric and metabolic characteristics of 5,645 middle-aged Danish Inter99 participants stratified according to AGPAT6 rs999188 (Table S2), 12677439 (Table S3), rs6988044 (Table S4), rs2977860 (Table S5), rs13252523 (Table S6), rs2977845 (Table S7), rs 11785763 (Table S8), rs7357415 (Table S9), and rs 10504041

(Table S10) genotypes. Data are mean \pm standard deviation. Values of serum insulin, the Stumvoll-S, and the Matsuda-S, were logarithmically transformed before analyses. P-values were calculated assuming an additive genetic model with adjustment for age and sex.

\section{Abbreviations}

AIR: Acute insulin response; BAT: Brown adipose tissue; GPAT4: Glycerol-3phosphate acyltransferase 4; HOMA: Homeostasis model assessment; LDs: Lipid droplets; OGTT: Oral glucose tolerance test; WAT: White adipose tissue.

\section{Competing interests}

D. R. Witte was employed by Steno Diabetes Center which is a teaching hospital facility working in the Danish National Health Service and owned by Novo Nordisk.

\section{Authors' contributions}

LSS collected and analysed the data and wrote the manuscript. NG, KB, MW analyzed the data and reviewed/edited the manuscript. TJ, DW, TL, AAN, IB, CC collected the patient data and reviewed/edited manuscript. OP, KY analysed the data and reviewed/edited manuscript. KH designed the study and wrote the manuscript. TH, JEH and HBN designed the study and reviewed/edited manuscript. All authors read and approved the final manuscript.

\section{Acknowledgements}

The study was supported by grants from the Lundbeck Foundation (www. lucamp.org), the Danish Medical Research Council and the Danish Council for Independent Research (Sapere Aude, DFF Starting Grant and post.doc. grant). The Novo Nordisk Foundation Center for Basic Metabolic Research is an independent Research Center at the University of Copenhagen partially funded by an unrestricted donation from the Novo Nordisk Foundation (www.metabol.ku.dk). The Inter99 study was initiated by Torben Jørgensen (PI), Knut Borch-Johnsen (co-PI), Troels Thomsen and Hans Ibsen. The present steering committee comprises the two former and Charlotta Pisinger. We would like to thank the Diagram Consortium (http://diagram-consortium.org/ downloads.html) for access to their newest GWAS data.

\section{Author details}

'Department of Endocrinology, Diabetes Research Center, Odense University Hospital, Odense, Denmark. ${ }^{2}$ Section of Molecular Diabetes \& Metabolism, Institute of Clinical Research \& Institute of Molecular Medicine, University of Southern Denmark, Odense, Denmark. ${ }^{3}$ The Novo Nordisk Foundation Center for Basic Metabolic Research, Faculty of Health and Medical Sciences, University of Copenhagen, Copenhagen, Denmark. ${ }^{4}$ Research Centre for Prevention and Health, Glostrup University Hospital, Glostrup, Denmark. ${ }^{5}$ Faculty of Health and Medical Sciences, University of Copenhagen, Copenhagen, Denmark. ${ }^{6}$ Steno Diabetes Center, Gentofte, Denmark. ${ }^{7}$ Department of General Practice, University of Aarhus, Aarhus, Denmark. ${ }^{8}$ Department of Clinical Biochemistry, Vejle Hospital, Vejle, Denmark. ${ }^{9}$ Institute of Regional Health Research, University of Southern Denmark, Odense, Denmark. ${ }^{10}$ Department of Internal Medicine and Endocrinology, Vejle Hospital, Vejle, Denmark. ${ }^{11}$ Faculty of Health Sciences, University of Aarhus, Aarhus, Denmark. ${ }^{12}$ Hagedorn Research Institute, Gentofte, Denmark.

Received: 18 February 2013 Accepted: 21 October 2013

Published: 25 October 2013

\section{References}

1. Farese RV Jr, Walther TC: Lipid droplets finally get a little R-E-S-P-E-C-T. Cell 2009, 139:855-860

2. Pan DA, Lillioja $S$, Kriketos $A D$, Milner MR, Baur LA, Bogardus $C$, Jenkins $A B$, Storlien $L H$ : Skeletal muscle triglyceride levels are inversely related to insulin action. Diabetes 1997, 46:983-988. 
3. Jacob S, Machann J, Rett K, Brechtel K, Volk A, Renn W, Maerker E, Matthaei S, Schick F, Claussen CD, Häring HU: Association of increased intramyocellular lipid content with insulin resistance in lean nondiabetic offspring of type 2 diabetic subjects. Diabetes 1999, 48:1113-1119.

4. Levin K, Daa Schroeder H, Alford FP, Beck-Nielsen H: Morphometric documentation of abnormal intramyocellular fat storage and reduced glycogen in obese patients with type II diabetes. Diabetologia 2001, 44:824-833.

5. Virkamäki A, Korsheninnikova E, Seppälä-Lindroos A, Vehkavaara S, Goto T, Halavaara J, Häkkinen AM, Yki-Järvinen H: Intramyocellular lipid is associated with resistance to in vivo insulin actions on glucose uptake, antilipolysis, and early insulin signaling pathways in human skeletal muscle. Diabetes 2001, 50:2337-2343.

6. DeFronzo RA: Insulin resistance, lipotoxicity, type 2 diabetes and atherosclerosis: the missing links. The Claude Bernard lecture 2009. Diabetologia 2010, 53:1270-1287.

7. Lettner A, Roden M: Ectopic fat and insulin resistance. Curr Diab Rep 2008, 8:185-191.

8. Szendroedi J, Roden M: Ectopic lipids and organ function. Curr Opin Lipidol 2009, 20:50-56.

9. Semple RK, Savage DB, Cochran EK, Gorden P, O'Rahilly S: Genetic syndromes of severe insulin resistance. Endocr Rev 2011, 32:498-514.

10. Takeuchi K, Reue K: Biochemistry, physiology, and genetics of GPAT, AGPAT, and lipin enzymes in triglyceride synthesis. Am J Physio Endocrinol Metab 2009, 296:E1195-E1209.

11. Chen YQ, Kuo MS, Li S, Bui HH, Peake DA, Sanders PE, Thibodeaux SJ, Chu S, Qian YW, Zhao Y, Bredt DS, Moller DE, Konrad RJ, Beigneux AP, Young SG, Cao G: AGPAT6 is a novel microsomal glycerol-3-phosphate acyltransferase. J Biol Chem 2008, 283:10048-10057.

12. Nagle CA, Vergnes L, Dejong H, Wang S, Lewin TM, Reue K, Coleman RA: Identification of a novel sn-glycerol-3-phosphate acyltransferase isoform, GPAT4, as the enzyme deficient in Agpat6-/- mice. J Lipid Res 2008, 49:823-831.

13. Vergnes L, Beigneux AP, Davis R, Watkins SM, Young SG, Reue K: Agpat6 Deficiency causes subdermal lipodystrophy and resistance to obesity. J Lipid Res 2006, 47:745-754.

14. Shan D, Li JL, Wu L, Li D, Hurov J, Tobin JF, Gimeno RE, Cao J: GPAT3 and GPAT4 are regulated by insulin-stimulated phosphorylation and play distinct roles in adipogenesis. J Lipid Res 2010, 51:1971-1981.

15. Li D, Yu L, Wu H, Shan Y, Guo J, Dang Y, Wei Y, Zhao S: Cloning and identification of the human LPAAT-zeta gene, a novel member of the lysophosphatidic acid acyltransferase family. J Human Genet 2003, 48:438-442

16. Jorgensen T, Borch-Johnsen $K$, Thomsen TF, Ibsen H, Glumer C, Pisinger C: A randomized non-pharmacological intervention study for prevention of ischaemic heart disease: baseline results Inter99. Eur J Cardiovasc Prev Rehabil 2003, 10:377-386.

17. Lauritzen T, Griffin S, Borch-Johnsen K, Wareham NJ, Wolffenbuttel BH, Rutten G: The ADDITION study: proposed trial of the cost-effectiveness of an intensive multifactorial intervention on morbidity and mortality among people with type 2 diabetes detected by screening. Int J ObesRelat Metab Disord 2000, 3(24 Suppl):S6-S11.

18. Albrechtsen A, Grarup N, Li Y, Sparsø T, Tian G, Cao H, Jiang T, Kim SY, Korneliussen T, Li Q, Nie C, Wu R, Skotte L, Morris AP, Ladenvall C, Cauchi S, Stančáková A, Andersen G, Astrup A, Banasik K, Bennett AJ, Bolund L, Charpentier G, Chen Y, Dekker JM, Doney AS, Dorkhan M, Forsen T, Frayling TM, Groves CJ, et al: Exome sequencing-driven discovery of coding polymorphisms associated with common metabolic phenotypes. Diabetologia 2013, 56(2):298-310.

19. World Health Organisation: Definition, diagnosis and classification of diabetes mellitus: report of a WHO consultation. Geneva, Switzerland: World Health Organisation; 1999. WHO/NCD/NCS/99.2.

20. Matthews DR, Hosker JP, Rudenski AS, Naylor BA, Treacher DF, Turner RC: Homeostasis model assessment: insulin resistance and beta-cell function from fasting plasma glucose and insulin concentrations in man. Diabetologia 1985, 28:412-419.

21. Hansen T, Drivsholm T, Urhammer SA, Palacios RT, Vølund A, Borch-Johnsen $K$, Pedersen O: The BIGTT test: a novel test for simultaneous measurement of pancreatic beta-cell function, insulin sensitivity, and glucose tolerance. Diabetes Care 2007, 30:257-262.
22. Matsuda M, DeFronzo RA: Insulin sensitivity indices obtained from oral glucose tolerance testing: comparison with the euglycemic insulin clamp. Diabetes Care 1999, 22:1462-1470.

23. Stumvoll M, Van HT, Fritsche A, Gerich J: Oral glucose tolerance test indexes for insulin sensitivity and secretion based on various availabilities of sampling times. Diabetes Care 2001, 24:796-797.

24. Morris AP, Voight BF, Teslovich TM, Ferreira T, Segrè AV, Steinthorsdottir V, Strawbridge RJ, Khan H, Grallert H, Mahajan A, Prokopenko I, Kang HM, Dina C, Esko T, Fraser RM, Kanoni S, Kumar A, Lagou V, Langenberg C, Luan J, Lindgren CM, Müller-Nurasyid M, Pechlivanis S, Rayner NW, Scott LJ, Wiltshire S, Yengo L, Kinnunen L, Rossin EJ, Raychaudhuri S, et al: Large-scale association analysis provides insights into the genetic architecture and pathophysiology of type 2 diabetes. Nat Genet 2012, 44(9):981-990

25. Taskinen MR: Diabetic dyslipidaemia: from basic research to clinical practice. Diabetologia 2003, 46:733-749.

26. Saxena R, Voight BF, Lyssenko V, Burtt NP, de Bakker PIW, Chen H, Roix JJ, Kathiresan S, Hirschhorn JN, Daly MJ, Hughes TE, Groop L, Altshuler D, Almgren P, Florez JC, Meyer J, Ardlie K, Boström KB, Isomaa B, Lettre G, Lindblad U, Lyon HN, Melander O, Newton-Cheh C, Nilsson P, Ohro-Melander M, Råstam L, Speliotes EK, Taskinen MR, Tuomi T, et al: Genome-wide association analysis identifies loci for type 2 diabetes and triglyceride levels. Science 2007, 316:1331-1336.

27. Scott LJ, Mohlke KL, Bonnycastle LL, Willer CJ, Li Y, Duren WL, Erdos MR, Stringham HM, Chines PS, Jackson AU, Prokunina-Olsson L, Ding CJ, Swift AJ, Narisu N, Hu T, Pruim R, Xiao R, Li XY, Conneely KN, Riebow NL, Sprau AG, Tong M, White PP, Hetrick KN, Barnhart MW, Bark CW, Goldstein JL, Watkins L, Xiang F, Saramies J, et al: A genome-wide association study of type 2 diabetes in Finns detects multiple susceptibility variants. Science 2007, 316:1341-1345.

28. Zeggini E, Scott LJ, Saxena R, Voight BF, Marchini JL, Hu T, de Bakker PIW, Abecasis GR, Almgren P, Andersen G, Ardlie K, Boström KB, Bergman RN, Bonnycastle LL, Borch-Johnsen K, Burtt NP, Chen H, Chines PS, Daly MJ, Deodhar P, Ding CJ, Doney AS, Duren WL, Elliott KS, Erdos MR, Frayling TM, Freathy RM, Gianniny L, Grallert H, Grarup N, et al: Meta-analysis of genomewide association data and large-scale replication identifies additional susceptibility loci for type 2 diabetes. Nat Genet 2008, 40:638-645.

29. Sladek R, Rocheleau G, Rung J, Dina C, Shen L, Serre D, Boutin P, Vincent D, Belisle A, Hadjadj S, Balkau B, Heude B, Charpentier G, Hudson TJ, Montpetit A, Pshezhetsky AV, Prentki M, Posner BI, Balding DJ, Meyre D, Polychronakos C, Froguel P: A genome-wide association study identifies novel risk loci for type 2 diabetes. Nature 2007, 445:881-885.

30. Grarup N, Sparso T, Hansen T: Physiologic characterization of type 2 diabetes-related loci. Curr Diab Rep 2010, 10:485-497.

31. Agarwal AK, Arioglu E, Almeida SD, Akkoc N, Taylor SI, Bowcock AM, Barnes RI, Garg A: AGPAT2 is mutated in congenital generalized lipodystrophy linked to chromosome 9q34. Nat Genet 2002, 31:21-23.

32. Cortes VA, Curtis DE, Sukumaran $S$, Shao X, Parameswara V, Rashid S, Smith AR, Ren J, Esser V, Hammer RE, Agarwal AK, Horton JD, Garg A: Molecular mechanisms of hepatic steatosis and insulin resistance in the AGPAT2-deficient mouse model of congenital generalized lipodystrophy. Cell Metab 2009, 9:165-176.

33. Johansen $C T$, Hegele RA: Genetic bases of hypertriglyceridemic phenotypes. Curr Opin Lipidol 2011, 22:247-253.

34. Hucking K, Watanabe RM, Stefanovski D, Bergman RN: OGTT-derived measures of insulin sensitivity are confounded by factors other than insulin sensitivity itself. Obesity (Silver Spring) 2008, 16:1938-1945

35. Cohen JC, Horton JD, Hobbs HH: Human fatty liver disease: old questions and new insights. Science 2011, 332:1519-1523.

36. Speliotes EK, Yerges-Armstrong LM, Wu J, Hernaez R, Kim $\sqcup$, Palmer CD, Gudnason V, Eiriksdottir G, Garcia ME, Launer L, Nalls MA, Clark JM, Mitchell BD, Shuldiner AR, Butler JL, Tomas M, Hoffmann U, Hwang SJ, Massaro JM, O'Donnell CJ, Sahani DV, Salomaa V, Schadt EE, Schwartz SM, Siscovick DS NASHCRN, Consortium GIANT, Investigators MAGIC, Voight BF, Carr JJ, Feitosa MF, et al: Genome-wide association analysis identifies variants associated with nonalcoholic fatty liver disease that have distinct effects on metabolic traits. PLOS Genet 2011, 7:e1001324.

doi:10.1186/1471-2350-14-113

Cite this article as: Snogdal et al: Studies of association of AGPAT6 variants with type 2 diabetes and related metabolic phenotypes in 12,068 Danes. BMC Medical Genetics 2013 14:113. 